\title{
Effects of caudate lesions on the acquisition and retention of Sidman avoidance in the rat
}

\author{
JOSEPH D. ALLEN and JUDSON C. MITCHAM \\ University of Georgia, Athens, Ga. 30601 \\ and \\ JAMES I. BYRD \\ University of Texas, Austin, Tex. 78712
}

Rats with caudate lesions were compared with normals and controls on a nonsignaled Sidman avoidance schedule. Though acquisition rates were generally comparable, performance for caudates was permanently impaired during both acquisition and retention tests. Caudate Ss adopted an inefficient response pattern which was characterized by sustained postshock response bursts followed by long pauses and which resulted in substantially higher shock rates.

Investigations of the effects of bilateral damage to the caudate nucleus upon the acquisition and performance of avoidance behavior have yielded inconsistent findings. Tasks requiring rats with caudate lesions to shuttle in both directions have either revealed marked performance deficits (Green, Beatty, \& Schwartzbaum, 1967 ; Neill \& Grossman, 1970) or no deficit at all (Fox, Kimble, \& Lickey, 1964; Albert \& Bignami, 1968). Likewise, performance in a one-way shuttle avoidance task has been reported to be either impaired (Kirkby \& Kimble, 1968 ) or apparently normal (Winocur \& Mills, 1969).

To date, the performance of caudate-damaged rats on a free operant or Sidman avoidance schedule (Sidman, 1953) has not been assessed. In the present study, brief footshocks were delivered to the $S$ at $5-\mathrm{sec}$ intervals (S-S interval) if no response was emitted. A leverpress postponed the shock for $20 \mathrm{sec}$ (R-S interval), and, if no additional shock postponements were occasioned by intervening responses, the shocks were resumed at the 5-sec S-S interval. Maximally efficient performance on this schedule results if $S$ spaces out its responses at intervals just shorter than the R-S interval, since this affords maximal shock frequency reduction at minimal response output. Although this optimal response pattern is seldom achieved, the schedule permits effective shock frequency reduction in spite of considerable variation in response rate and distribution.

SUBJECTS AND APPARATUS

Eight male Holtzman rats, between 120 and 150 days of age, served as Ss. They were individually housed and had free access to food and water in the home cage. Two Lehigh Valley Electronics (Model 1417) operant conditioning chambers, equipped with retractable levers, were used. Brief 0.3 -sec shocks of $1.2 \mathrm{~mA}$ intensity were delivered to the grid floor via
The remaining four $S s$ received electrode track control operations following avoidance training and stabilization. Identical coordinates were used, except that the electrode was lowered $3.2 \mathrm{~mm}$ to the top of the caudate and no current was passed. Since two Ss ( $1 \mathrm{~N}$ and $3 \mathrm{~N}$ ) expired during surgery, postoperative recovery data were available only from Ss $7 \mathrm{NCo}$ and 9NCo. Two-week postoperative recovery periods were allowed prior to testing.

The Ss received daily 4 -h sessions on the Sidman avoidance schedule, which programmed 5 -sec S-S and 20 -sec R-S intervals throughout the study. Autoshaping of the leverpress response was facilitated (Bolles \& Popp, 1964; Elliot \& King, 1970) by arranging shock postponements for both downward and upward movements of the lever and by correlating each response with a brief flash from a $20-\mathrm{V}$ ac dial light mounted above the lever. The double operation of the lever was designed to reinforce a release response in the $S s$ and was discontinued after 7.10 sessions. Thereafter, only lever depressions postponed shocks and produced the feedback stimulus. Ss were given approximately 20 additional sessions until shock rates and response rates showed no. consistent change for a 5-day period. Postoperative retention sessions began 14 days following surgery and continued until stability was reachieved.

At the completion of the study, Ss were sacrificed and perfused
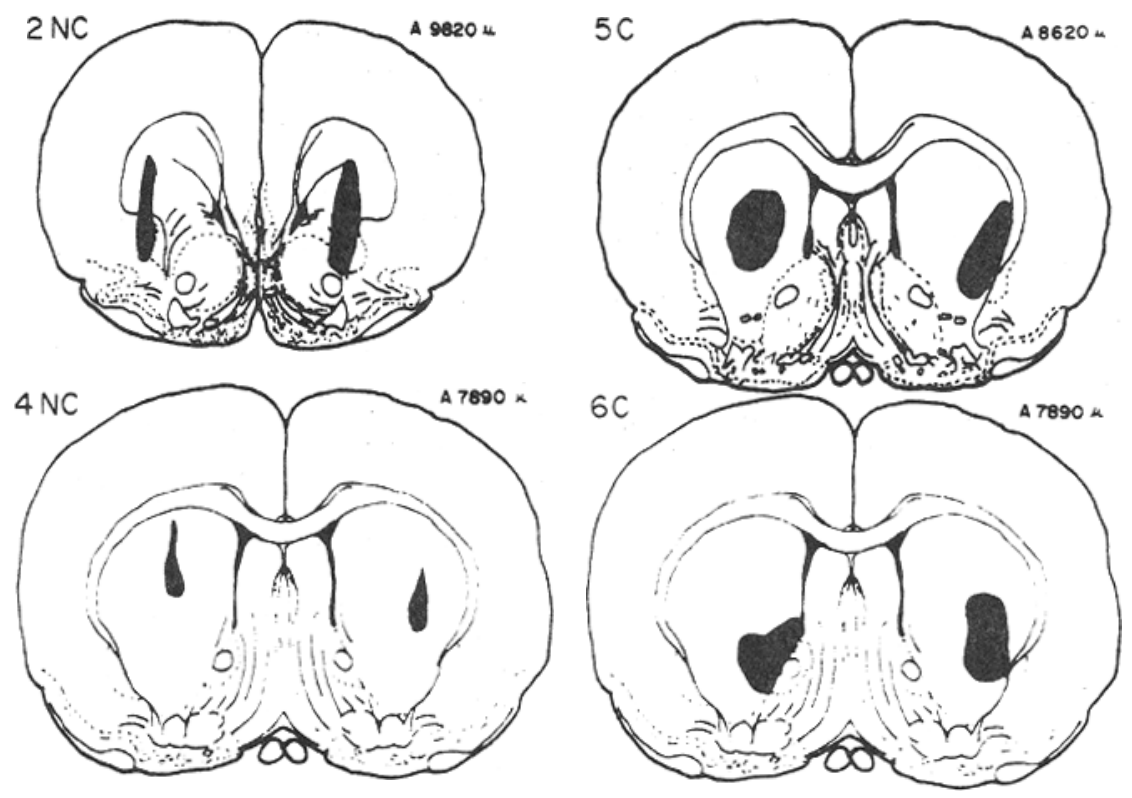

Fig. 1. Reconstructions of caudate lesions in the plane of maximal involvement. Anterior coordinate of each section, reproduced from König \& Klippel (1963), appears in the upper right corner. 

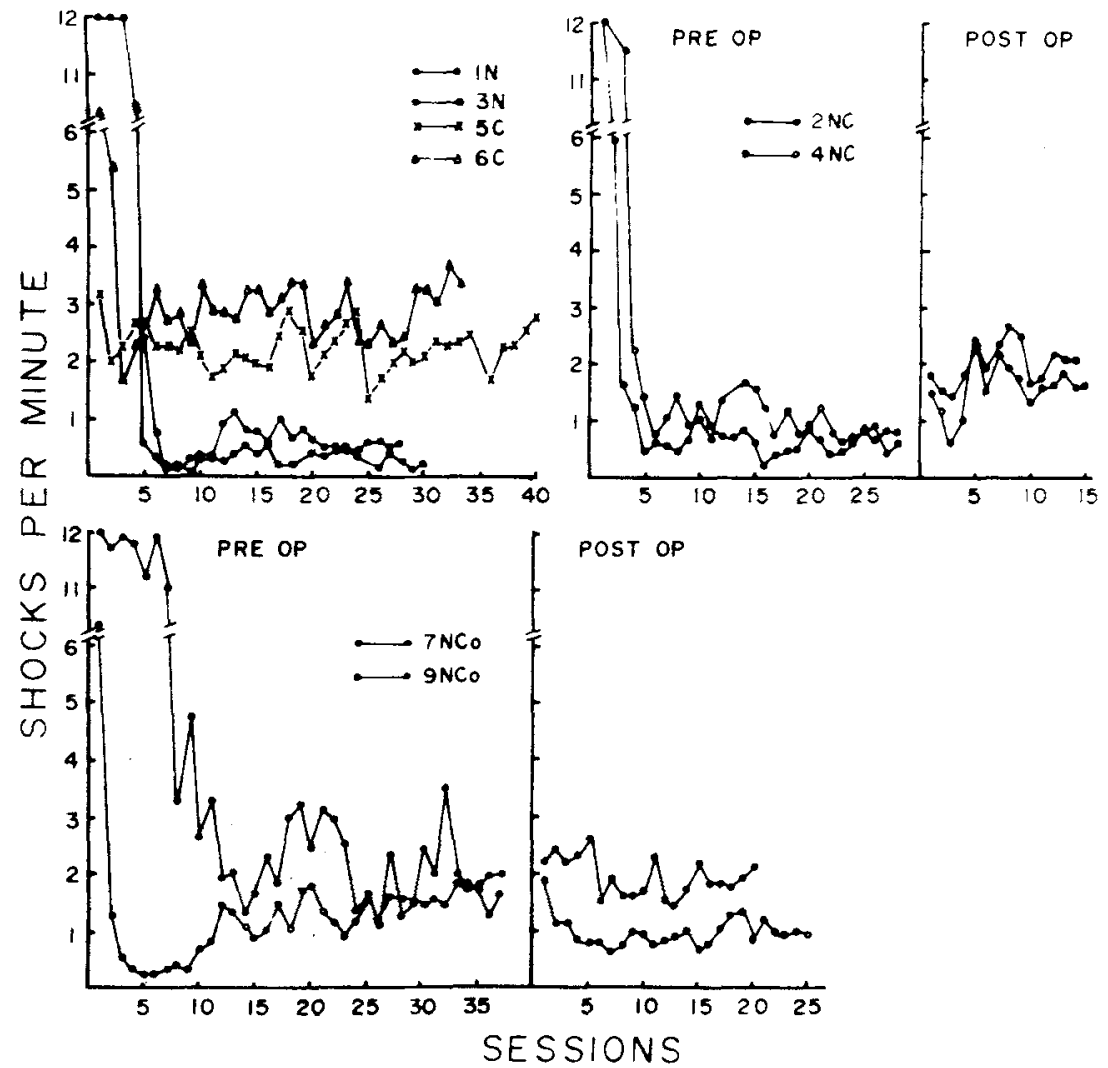

Fig. 2. Shock rates for each animal over the last $3 \mathrm{~h}$ of each session. $\mathrm{N}=$ normal, $\mathbf{C}=$ caudate, $\mathrm{NC}=$ normal during acquisition and caudate during retention sessions, $\mathrm{NCo}=$ normal during acquisition and electrode track control during retention sessions.

intracardially with saline and $10 \%$ Formalin. The brains were embedded in celloidin and sectioned at 30 micrometers. Every fourth and fifth section was mounted and stained with thionin and weil stain, respectively.

\section{RESULTS AND DISCUSSION}

As shown in Fig. 1, the lesions were between 0.5 and $1.5 \mathrm{~mm}$ in diam and were largely confined to the middle and ventral portion of the head of the caudate. S 6C received the largest lesions, which extended $3.4 \mathrm{~mm}$ in a posterior direction from the rostral tip of the caudate and which incurred some bilateral damage to the nucleus accumbens and anterior commissure and slight unilateral damage to the corpus callosum, claustrum, and lateral septal nucleus. $S 4 N C$ sustained the smallest lesions, which extended $1.0 \mathrm{~mm}$ in the AP plane. The lesions were completely confined to the caudate nucleus and had more dorsal placements. Considerable distension of the lateral ventricles was evidenced in all operated Ss.

All behavioral data were collected during the last $3 \mathrm{~h}$ of the session to eliminate the initial behavior variability known as warm-up. Figure 2 indicates that under normal conditions, Ss required between two and six sessions to acquire a persistent leverpress response. The majority of Ss were receiving less than one shock per minute when performance had stabilized.

Though not impaired in acquiring the leverpress response, caudate lesion Ss $5 \mathrm{C}$ and $6 \mathrm{C}$ (upper left panel) sustained stable shock rates (2.4 and 3.4 shocks/min) which were well above those sustained by the normal and electrode track control Ss. With respect to an index of relative shock avoidance, $5 \mathrm{C}$ and $6 \mathrm{C}$ avoided $80.4 \%$ shocks during a session, while normal Ss avoided $95.0 \%$ of the shocks. As indicated by the upper right panel, postoperative shock rates for Ss $2 \mathrm{NC}$ and $4 \mathrm{NC}$ immediately increased to levels which were two to three times their preoperative rates $(0.7$ to 2.1 and 0.7 to 1.6 shocks $/ \mathrm{min}$ ), while shock avoidance percentages dropped from $94.0 \%$ to $82.7 \%$ and $86.6 \%$, respectively.

Stabilized response rates among normal Ss varied between 4.2 and 10.6 responses per minute, and the grain of smooth, indicating that the Ss were spacing out their responses in the R-S and $71.6 \%$ of the total scheduled their cumulative records was typically interval. Response rates among the lesioned $S s$ displayed a comparable range; however, as evidenced by a stepwise feature of their records, the predominant response pattern was to burst following each shock and then to wait out the R-S interval. The postshock burst pattern typifies the initial phase of avoidance conditioning with most normal Ss, and results when the periodic delivery of shock momentarily disrupts a persistent leverholding behavior in $\mathrm{S}$ by eliciting a brief burst of leverpresses. Although eventually abandoned by all normal Ss, the postshock burst pattern persisted with Caudates $5 \mathrm{C}$ and $6 \mathrm{C}$, which received lesions prior to training, and was readopted by Ss $2 \mathrm{NC}$ and $4 \mathrm{NC}$, which received lesions after efficient responding had already been well established preoperatively.

The response probability distributions in Fig. 3 provide a quantitative comparison between the response patterns adopted by the Ss when under normal, control, and operated conditions. The interresponse time (IRT) distributions (histograms) portray the percentage of total responses that occurred in each consecutive 2-sec segment of the R-S interval. For caudates, between $20 \%$ and $30 \%$ of the total responses produced during the session terminated an S-S interval (>20-sec bin), and another $47 \%$ to $60 \%$ were short $0-2$-sec IRTs. Since the initial response comprising a postshock burst would be assigned to the $>20-\mathrm{sec}$ bin and all remaining responses in the burst would be assigned to the $0 \cdot 2-\mathrm{sec}$ bin, the combined value of the two bins would reflect the amount of postshock bursting, which for caudate Ss ranged between $68 \%$ and $85 \%$. Thus, only $15 \%$ to $32 \%$ of the total responses were distributed throughout the remainder of the $R-S$ interval. In contrast, normals and controls distributed a smaller percentage of responses into the $>20-\sec (3 \%$ to $9 \%$ ) and $0-2-\sec (16 \%$ to $42 \%)$ bins, leaving a substantially larger percentage $(46 \%$ to $76 \%$ ) to be distributed more efficiently over the longer IRT classes of the R-S interval.

Interresponse times per opportunity (IRT/op) functions were also displayed (polygons), since Anger (1963) has convincingly demonstrated that they provide a more sensitive indicator of temporal discrimination than do IRT distributions. The IRTs/op function represents the conditional probability that a response will occur at any time during the R-S interval, given that the $S$ has not prevented its opportunity by responding earlier in the interval. Evidence of a temporal discrimination is indicated by an IRTs/op curve 

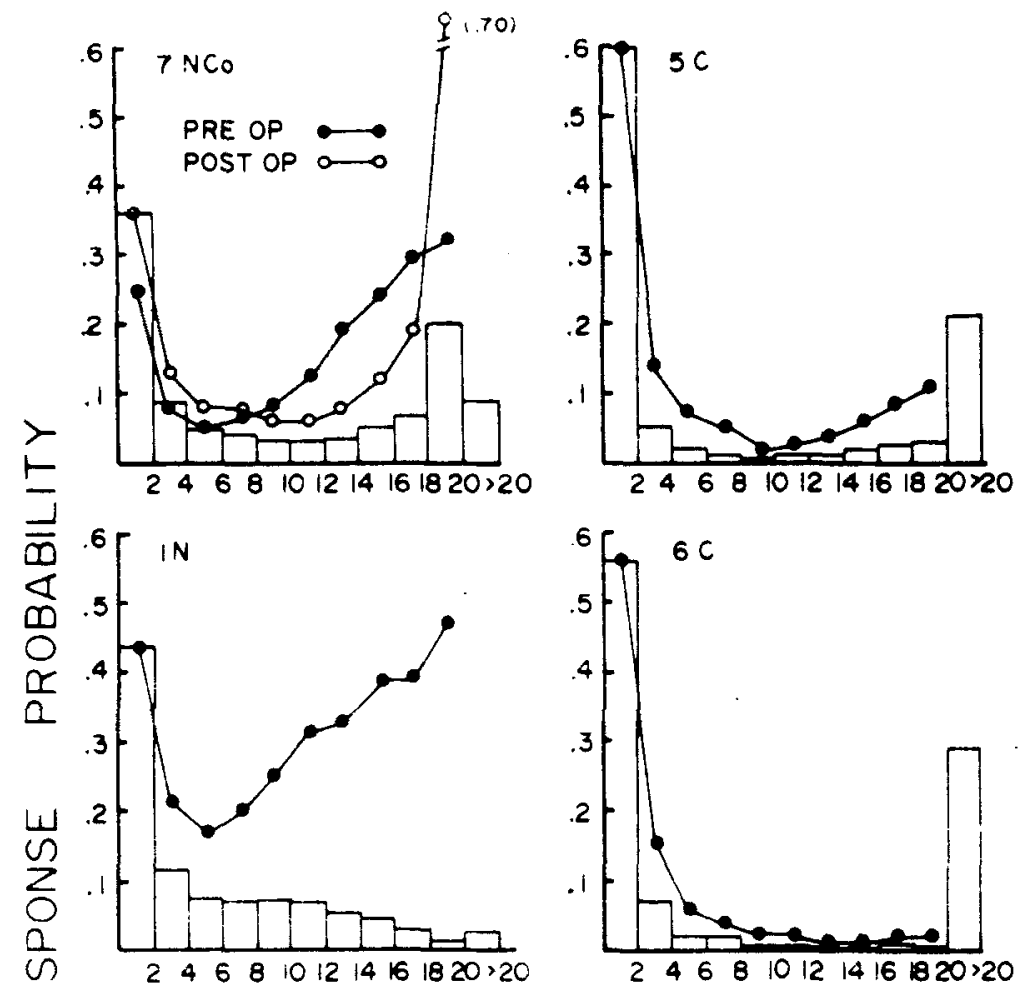

$2468101214161820 \times 20$
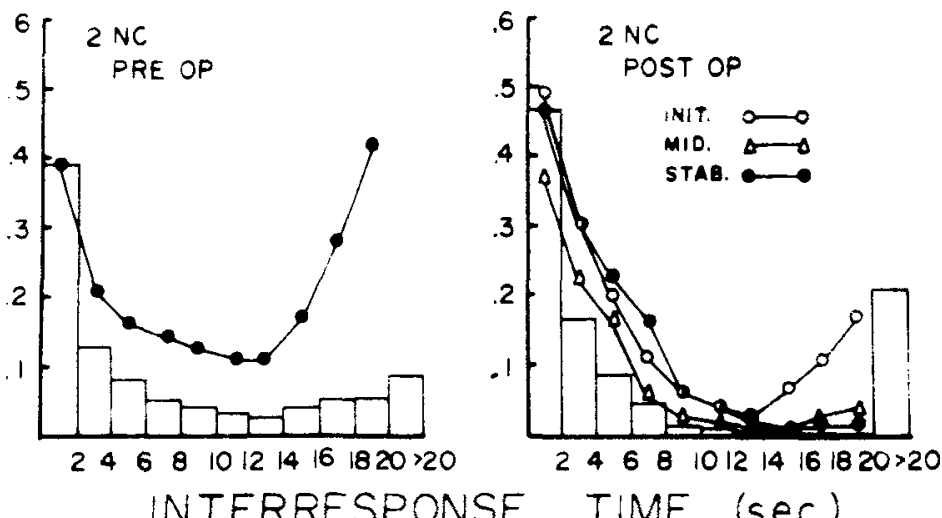

Fig. 3. Mean IRT (histograms) and corresponding IRTs/op (polygons) distributions for representative normal, control, and pre- and postacquisition caudate Ss. The probability of a response during each of 102 -sec class intervals and in a $>20$-sec class interval is averaged over the final five sessions in each training condition. For S $2 \mathrm{NC}$, IRTs/op functions are averages of the initial, middle, and final three postoperative sessions, and the IRT distribution is averaged over the final three postoperative sessions.

which is low at shorter IRTs and rises at longer IRTs, with a steeper slope denoting a sharper temporal discrimination. All normal and track control Ss showed evidence of having established a temporal discrimination. The IRTs/op functions of the track control Ss continued to steepen postoperatively. By comparison, evidence of a temporal discrimination was exceedingly small or virtually absent in Ss $5 \mathrm{C}$ and $6 \mathrm{C}$ which were trained with caudate lesions. Both 2NC and $4 N C$, which had established a temporal discrimination during preoperative sessions, appeared to have retained some of the spaced-response pattern during the first three postoperative sessions; however, this pattern disappeared completely in later sessions.

Caudate lesions clearly resulted in a permanent performance deficit on a free-operant avoidance schedule, thus extending the range of avoidance tasks in which a deficit has been reported. With the Sidman task, there are a number of factors which could be held responsible for the deficit. First of all, the lesions could have prevented Ss f rom ab a n d o n ing the freezing-on-the-lever behavior, and thus prevented their learning a more efficient spaced-response pattern. This explanation, although plausible for the Ss trained after receiving lesions, cannot easily handle the readoption of the shock-burst pattern by Ss $2 \mathrm{NC}$ and $4 \mathrm{NC}$, which had already learned an efficient response pattern preoperatively.

Alternatively, the lesions may have permanently impaired Ss' ability to initiate a voluntary response sequence, while not disrupting the response-eliciting property of the shocks. If it may be assumed that the postshock burst represents elicited rather than emitted behavior, then only $15 \%$ to $32 \%$ of the responses during a session represented voluntary avoidance responses. The corresponding range for normal and control Ss was between $46 \%$ and $76 \%$ of the total responses. Furthermore, those responses which were emitted by the caudate $S s$ were not distributed efficiently within the R-S interval, which suggests that a timing deficit was also involved. As shown by the IRTs/op functions in Fig. 3 , the conditional probability of an avoidance response for caudates declined precipitously over the early segments of the R-S interval and failed to increase substantially in the later segments of the interval, as it did for the normal and control Ss. Several studies have already implicated the caudate nucleus with the control of timing behavior. Using a DRL reinforcement schedule, which requires the $S$ to pause for a specified interval between successive reinforced responses, Deadwyler \& Wyers (1970) reported that electrical stimulation of the caudate facilitated timing performance. Conversely, Schmaltz \& Isaacson (1967) reported that lesions in the caudate resulted in a temporary disruption of a preoperatively acquired temporal discrimination. A similar timing deficit appears to be present in performance on a free operant avoidance task; however, its involvement is permanent.

\section{REFERENCES}

ALBERT, M., \& BIGNAMI, G. Effects of frontal, median cortical, and caudate lesions on two-way avoidance learning by rats. Physiology \& Behavior, 1968, 3 140-148.

ANGER, D. The role of temporal discriminations in the reinforcement of Sidman avoidance behavior. Journal of the Experimental Analysis of Behavior 1963, 6(supplement), 477-506.

BOLLES, R. C., \& POPP, R. J., JR Parameters affecting the acquisition of Sidman avoidance. Journal of the Experimental Analy sis of Behavior, 1964 , 7, 315-321.

DEADWYLER, S. A WYERS, E,J. Effects of interpolated caudate and septal stimulation on DRL performance in rats. 
Proceedings, 78th Annual Convention, American Psychological Association, 1970, 241-242.

ELLIOT, J. M., \& KING, T. M. Acquisition of free-operant avoidance with response-contingent stimulus. Psychonomic Science, 1970, 20, 27-28.

FOX, S. S.. KIMBLE, D. P., \& LICKEY. M. $E$. Comparison of caudate nucleus and septal-area lesions on two types of avoidance behavior. Journal of Comparative \& Physiological Psychology, $1964,58,380-386$.

GREEN, $R$, H. BEATTY, w. W, \& SCHWARTZBAUM, J. S. Comparative effects of septo-hippocampal and caudate nucleus lesions on avoidance behavior in rats. Journal of Comparative \& Physiological Psychology, 1967, 64, 444-452.

KIRKBY, R. J. \& KIMBLE, D. P Avoidance and escape behavior following striatal lesions in the rat. Experimental Neurology, 1968, 20, 215-227.

KÖNIG, J. F., \& KLIPPEL, R, A. The rat brain: A stereotaxic atlas of the forebrain and lower parts of the brainstem. Baltimore: Williams \& Wilkins, 1963

NEILL, D. B., \& GROSSMAN, S. P. Behavioral effects of lesions or cholinergic blockade of the dorsal and ventral caudate of rats. Journal of
Comparative \& Physiological Psychology. 1970, 71, 311-317.

SCHMALTZ, L. W., \& ISAACSON, R. L Effects of caudate and frontal lesions on retention and relearning of a DRL schedule. Journal of Comparative \& Physiological Psychology. 1968. 65. 343-348.

SIDMAN, M. Avoidance conditioning with brief shock and no exteroceptive warning signal. Science, 1953, 118, 157-158.

WINOCUR, G., \& MILLS, J. A. Effect of caudate lesions on avoidance behavior in rats. Journal of Comparative \& Physiological Psychology, 1969, 68, 552-557. 